\title{
Effect of low-level laser therapy on pain levels in patients with temporomandibular disorders: systematic review
}

\author{
Mila Leite de Moraes MAIA ${ }^{1}$, Leonardo Rigoldi BONJARDIM², Jullyana de Souza Siqueira QUINTANS ${ }^{3}$, Maria Amália \\ Gonzaga RIBEIRO4, Luiz Guilherme Martins MAIA ${ }^{5}$, Paulo César Rodrigues CONTI ${ }^{6}$
}

\author{
1- Specialist in Orthodontics. Master's student in Health Sciences, Federal University of Sergipe, Aracaju, SE, Brazil. \\ 2- PhD, Professor, Department of Physiology, Federal University of Sergipe, Aracaju, SE, Brazil. \\ 3- Doctorate student in Health Sciences, Federal University of Sergipe, Aracaju, SE, Brazil. \\ 4- PhD, Professor, Department of Dentistry, Federal University of Sergipe, Aracaju, SE, Brazil. \\ 5- Doctorate student, Araraquara School of Dentistry, UNESP - Univ Estadual Paulista, Araraquara, SP, Brazil. \\ 6- PhD, Professor, Department of Prosthodontics. Bauru School of Dentistry, University of São Paulo, Bauru, SP, Brazil.
}

Corresponding address: Mila Leite de Moraes Maia - Rua Terêncio Sampaio, 309 - Bairro Grageru - 49025-700 - Aracaju - Sergipe - Brazil - Phone: +55 79 9959-2567 - e-mail: milademoraes@hotmail.com

Received: September 6, 2011 - Modification: October 8, 2011 - Accepted: November 6, 2011

\section{ABSTRACT}

\begin{abstract}
$\mathrm{T}$ emporomandibular disorders (TMD) are characterized by the presence of temporomandibular joint (TMJ) and/or masticatory muscle pain and dysfunction. Low-level laser is presented as an adjuvant therapeutic modality for the treatment of TMD, especially when the presence of inflammatory pain is suspected. Objective: To systematically review studies that investigated the effect of low level laser therapy (LLLT) on the pain levels in individuals with TMD. Material and Methods: The databases Scopus, Embase, Ebsco and PubMed were reviewed from January/2003 to October/2010 with the following keywords: laser therapy, low-level laser therapy, temporomandibular joint disorders, temporomandibular joint dysfunction syndrome, temporomandibular joint, temporomandibular, facial pain and arthralgia, with the inclusion criteria for intervention studies in humans. Exclusion criteria adopted were intervention studies in animals, studies that were not written in English, Spanish or Portuguese, theses, monographs, and abstracts presented in scientific events. Results: After a careful review, 14 studies fit the criteria for inclusion, of which, 12 used a placebo group. As for the protocol for laser application, the energy density used ranged from 0.9 to $105 \mathrm{~J} / \mathrm{cm}^{2}$, while the power density ranged from 9.8 to $500 \mathrm{~mW}$. The number of sessions varied from 1 to 20 and the frequency of applications ranged from daily for 10 days to 1 time per week for 4 weeks. A reduction in pain levels was reported in 13 studies, with 9 of these occurring only in the experimental group, and 4 studies reporting pain relief for both the experimental group and for the placebo. Conclusion: Most papers showed that LLLT seemed to be effective in reducing pain from TMD. However, the heterogeneity of the standardization regarding the parameters of laser calls for caution in interpretation of these results. Thus, it is necessary to conduct further research in order to obtain a consensus regarding the best application protocol for pain relief in patients with TMD.
\end{abstract}

Key words: Laser therapy. Temporomandibular joint disorders. Review.

\section{INTRODUCTION}

Temporomandibular disorders (TMD) is considered the most common cause of pain of non-dental origin ${ }^{25}$ in the orofacial region and encompasses a heterogeneous group of disorders with common features of psychophysiological orofacial pain, masticatory dysfunction, or both ${ }^{30}$.

Signs and symptoms of this dysfunction are present in $86 \%$ of the population, most frequently in women in the 30 year-old age group ${ }^{5}$. The prevalence of TMD (or symptoms suggestive of 
TMD) varies from $21.5 \%$ to $51.8 \% 4,12,17,34$

Among the several reported signs and symptoms of TMD, pain has, with no doubt, most debilitating and unbearable effect on the patient's life. It has been found that masticatory muscle pain is the chief complaint of patients with TMD, usually associated with tension and fatigue, ranging from mild sensitivity to extreme discomfort, and frequently worsened by function of the muscles involved ${ }^{12,17}$.

Contemporary orofacial pain concepts aim to prevent, cure, or alleviate signs and symptoms of pain morbidity, as well as to reduce their impact on the patient's quality of life. Because of TMD's multifactorial etiology and variety of clinical presentations, the treatment of this disorder is extensive and diverse, involving professionals from different areas and includes several therapies: low level laser therapy ${ }^{8,19,27}$, acupuncture ${ }^{22}$, transcutaneous electrical nerve stimulation $(\text { TENS })^{32}$, ultrasound ${ }^{15}$, massage ${ }^{2}$, pharmacotherapy ${ }^{24}$, use of occlusal splints ${ }^{28}$, and psychological treatment, among others.

The use of laser photobiomodulation to reduce TMD pain and promote anti-inflammatory effects has been of great interest in the recent literature. Currently, its classification is based on the interaction of laser with the target tissue in question. The term LLLT is used when working in compliance with the threshold of cell survival ${ }^{3}$. Karu ${ }^{18}$ (2001) stated that this is a non-thermal therapy that can promote cell and tissue alterations caused by different types of metabolic activation, such as: increased activity in the mitochondria and $\mathrm{Na}(+) / \mathrm{K}(+)$ pump, increased vascularization and the formation of fibroblasts, resulting in an increase in the recovery process and/ or tissue healing with non-invasive characteristics.

The use of laser has grown in all areas of dentistry especially for conditions such as TMD that involves obtaining analgesia and reducing inflammation. In general, patients are receptive to LLLT which also has a positive psychological effect especially in chronic patients ${ }^{31}$. The therapeutic properties of lasers, such as tissue repair, mediation of inflammatory processes, and analgesia in acute and chronic pain as well as improvement of local microcirculation have been proven by several authors $^{31}$.

Based on that, the aim of this study is to perform a systematic review of the effect of LLLT in the control of pain in patients with TMD.

\section{MATERIAL AND METHODS}

\section{Search strategy and inclusion criteria}

A literature search was performed to identify interventional studies involving the application of LLLT in patients with painful symptoms caused by TMD. The databases Scopus, Embase, Ebsco, and
PubMed were revised from January 2003 to October 2010. Results of previous studies on the same subject were already summarized and reported in a previous publication ${ }^{3}$.

The keywords laser therapy, low level laser therapy, temporomandibular joint disorders, temporomandibular joint dysfunction syndrome, temporomandibular joint, temporomandibular, facial pain, and arthralgia, were used either as MeSH (Medical Subject Headings is the NLM controlled vocabulary thesaurus used for indexing papers for PubMed) terms or as free-text in different combinations. We resorted to the logical operator "AND" to combine descriptors and terms used to trace publications. In the present study were only considered papers that used theses descriptors.

Two authors independently screened titles and abstracts for potential eligibility and the full texts for the final eligibility. The data were extracted using a standardized data collection form to record study design and methodological features, patient characteristics, interventions, outcomes, and missing outcome data. We chose not to include theses, monographs, and abstracts presented in events because the conducting of such a systematic search of the same is logistically unfeasible. Studies that focused on intervention in animals and those that were not written in English, Portuguese or Spanish were excluded.

The papers that met the inclusion criteria were carefully examined for the extraction of data, such as: study setting, including site and sample, age range, methods of diagnosis of TMD and pain assessment, sites of laser application, laser type, manufacturer, dose, application time, frequency or number of sessions per week, and pain outcomes.

\section{RESULTS}

The results are described in the following sequence (Figure 1):

- progressive selection of the studies and the

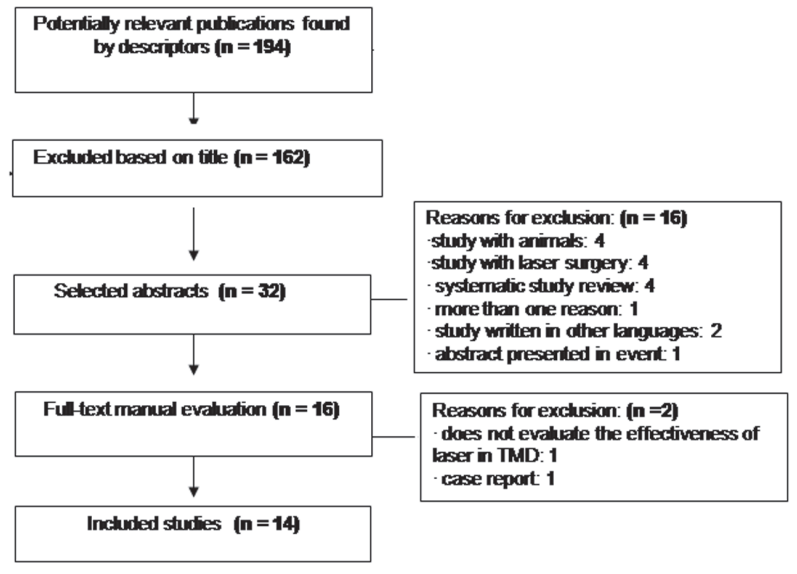

Figure 1- Flowchart of the selection phases of the study 
MAIA MLM, BONJARDIM LR, QUINTANS JSS, RIBEIRO MAG, MAIA LGM, CONTI PCR

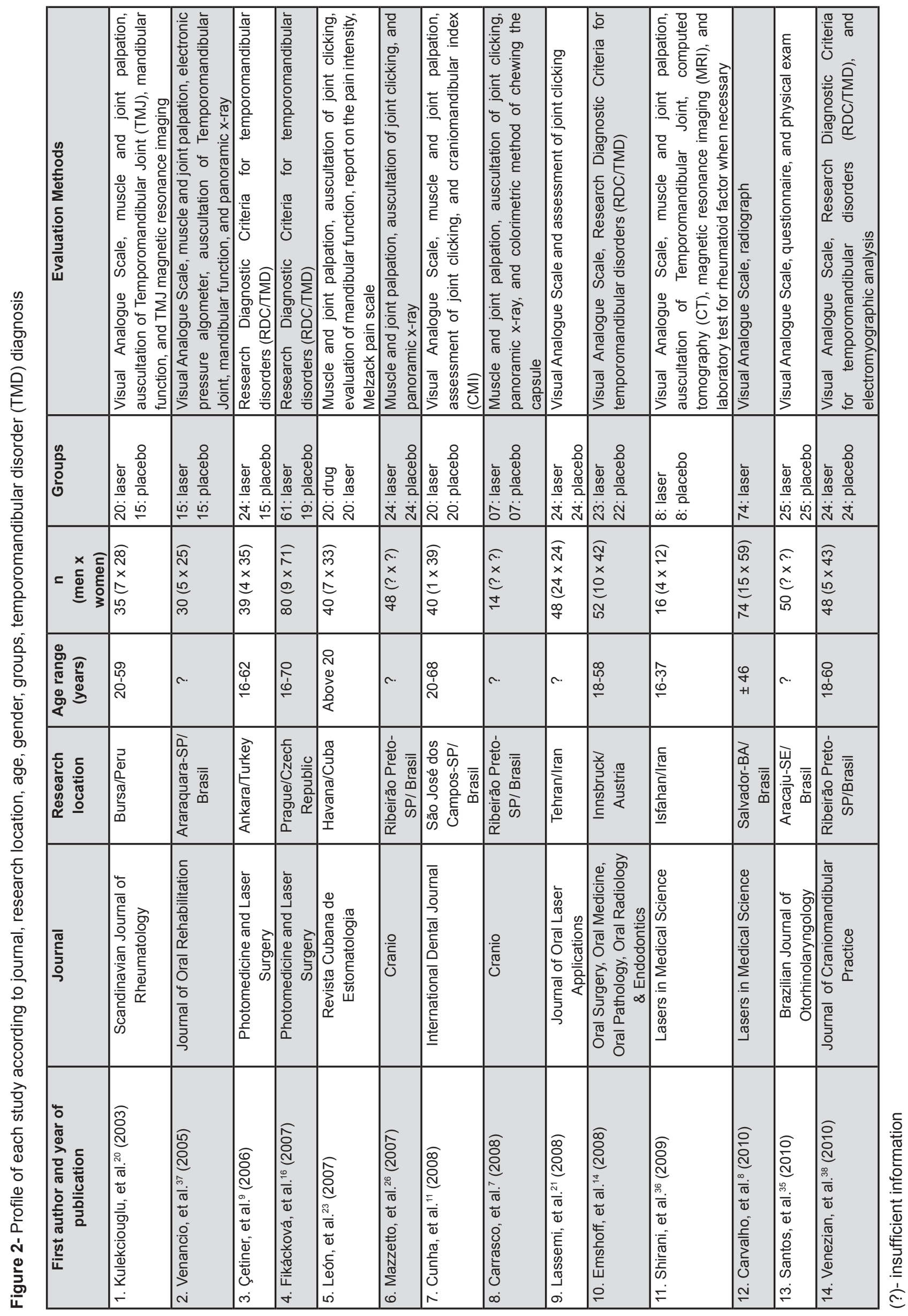


Effect of low-level laser therapy on pain levels in patients with temporomandibular disorders: a systematic review

\begin{tabular}{|c|c|c|c|c|c|c|c|c|c|}
\hline 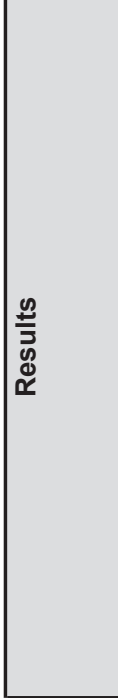 & 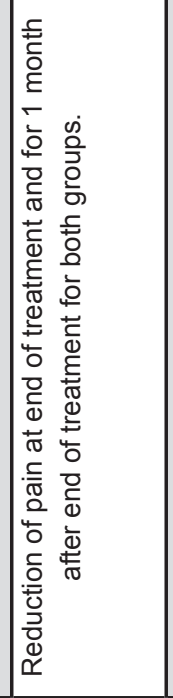 & 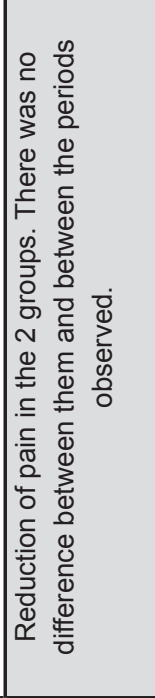 & 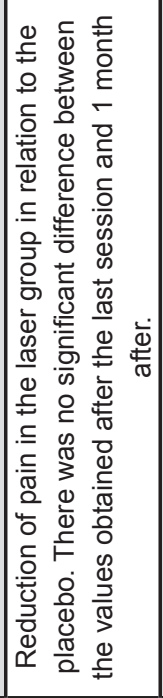 & 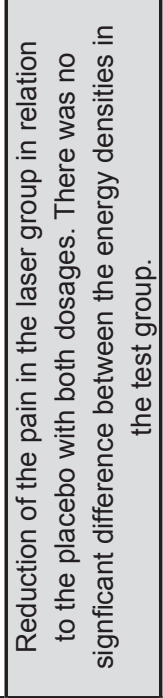 & 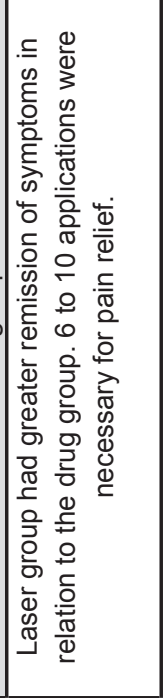 & 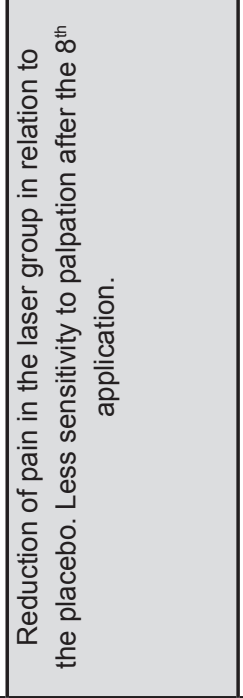 & 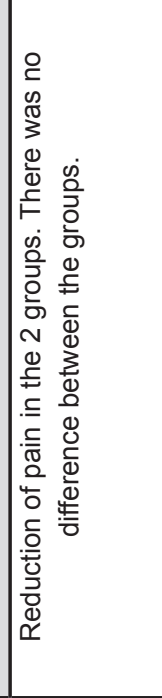 & 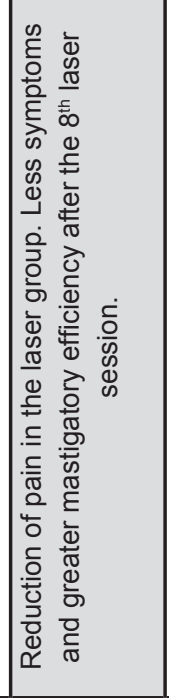 & 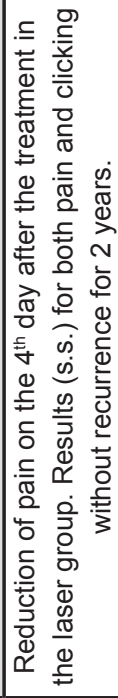 \\
\hline 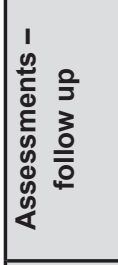 & 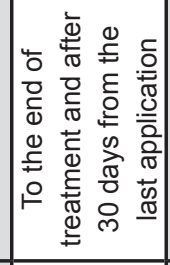 & 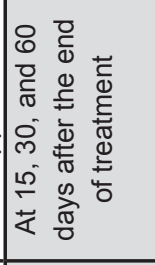 & 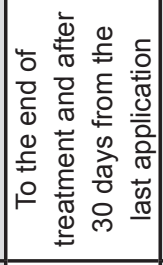 & 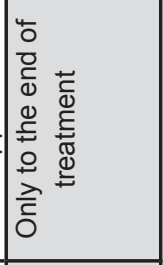 & 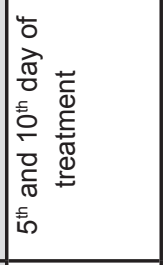 & 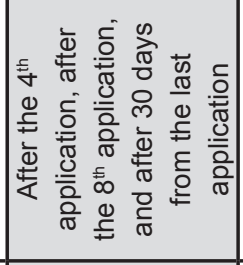 & 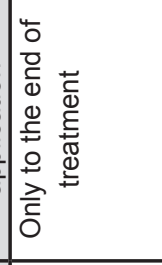 & 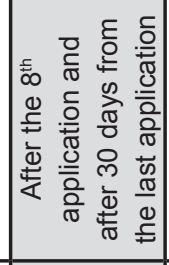 & 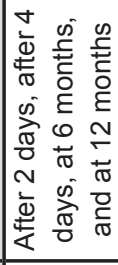 \\
\hline 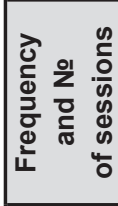 & 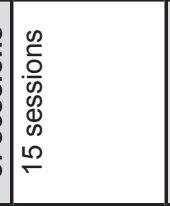 & 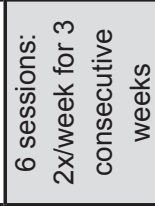 & 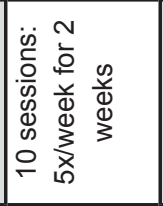 & 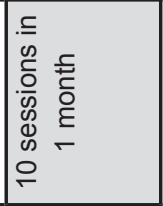 & 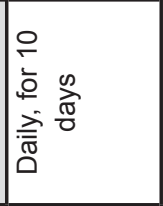 & 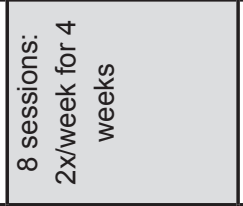 & 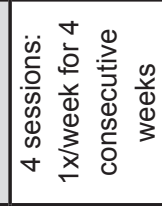 & 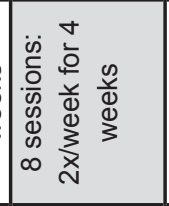 & 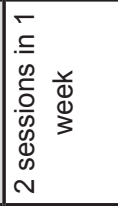 \\
\hline 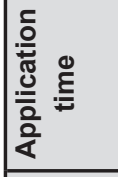 & & is & $\begin{array}{c}0 \\
\tilde{N} \\
\tilde{\sigma}\end{array}$ & r. & 离 & 里 & in & $\begin{array}{l}n \\
0 \\
0\end{array}$ & $\mid \begin{array}{l}0 \\
0 \\
0\end{array}$ \\
\hline 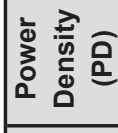 & $\mid \begin{array}{l}3 \\
\vdots \\
5\end{array}$ & $\begin{array}{l}3 \\
\text { ह } \\
0 \\
\text { ले }\end{array}$ & r. & \begin{tabular}{|l}
3 \\
E \\
8 \\
8 \\
\\
\end{tabular} & r. & $\mid \begin{array}{l}3 \\
\text { ह } \\
2 \\
2\end{array}$ & \begin{tabular}{|l}
3 \\
$z$ \\
8 \\
8 \\
0 \\
1
\end{tabular} & $\begin{array}{l}3 \\
z \\
0 \\
2\end{array}$ & r. \\
\hline 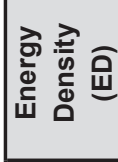 & $\mid \begin{array}{l}n \\
\frac{E}{0} \\
\\
m\end{array}$ & 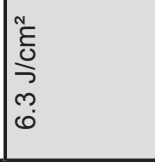 & 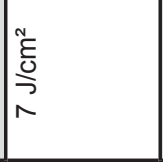 & 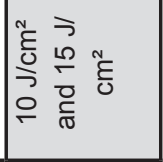 & 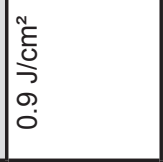 & 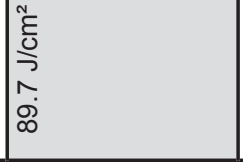 & 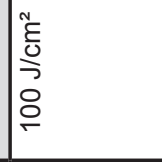 & 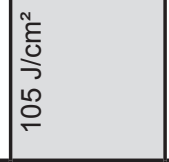 & 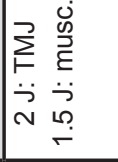 \\
\hline 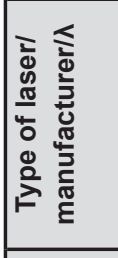 & 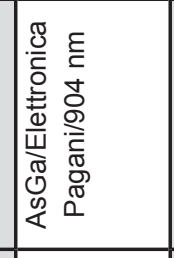 & 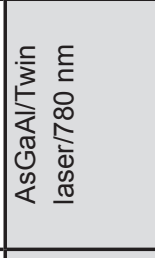 & 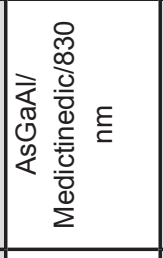 & 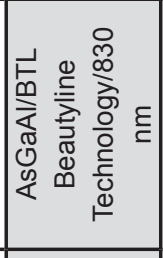 & 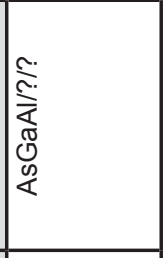 & 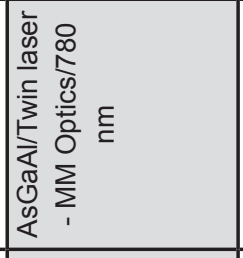 & 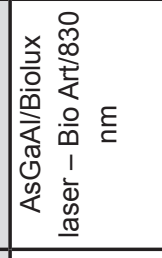 & 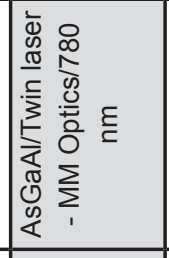 & 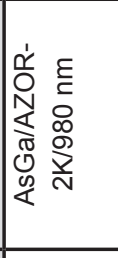 \\
\hline 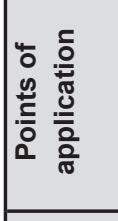 & 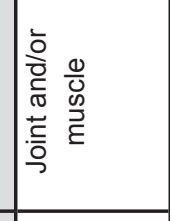 & 䓂 & 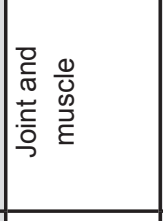 & 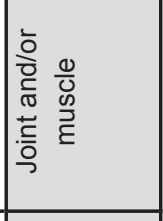 & 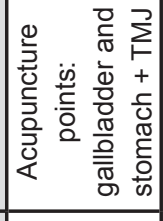 & 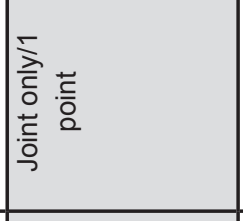 & 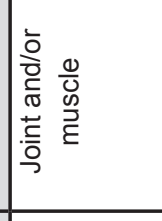 & 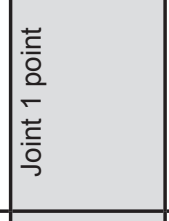 & 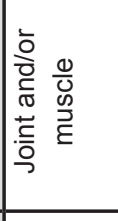 \\
\hline 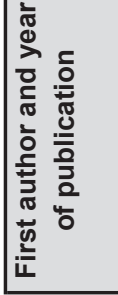 & 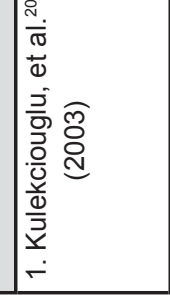 & 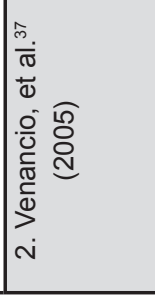 & 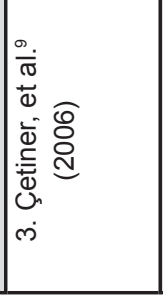 & 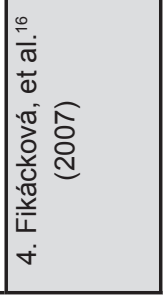 & 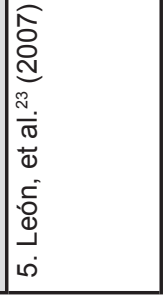 & 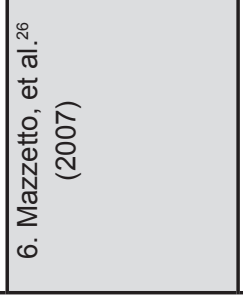 & 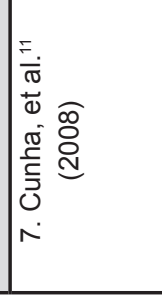 & 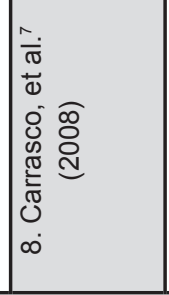 & 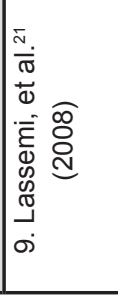 \\
\hline
\end{tabular}




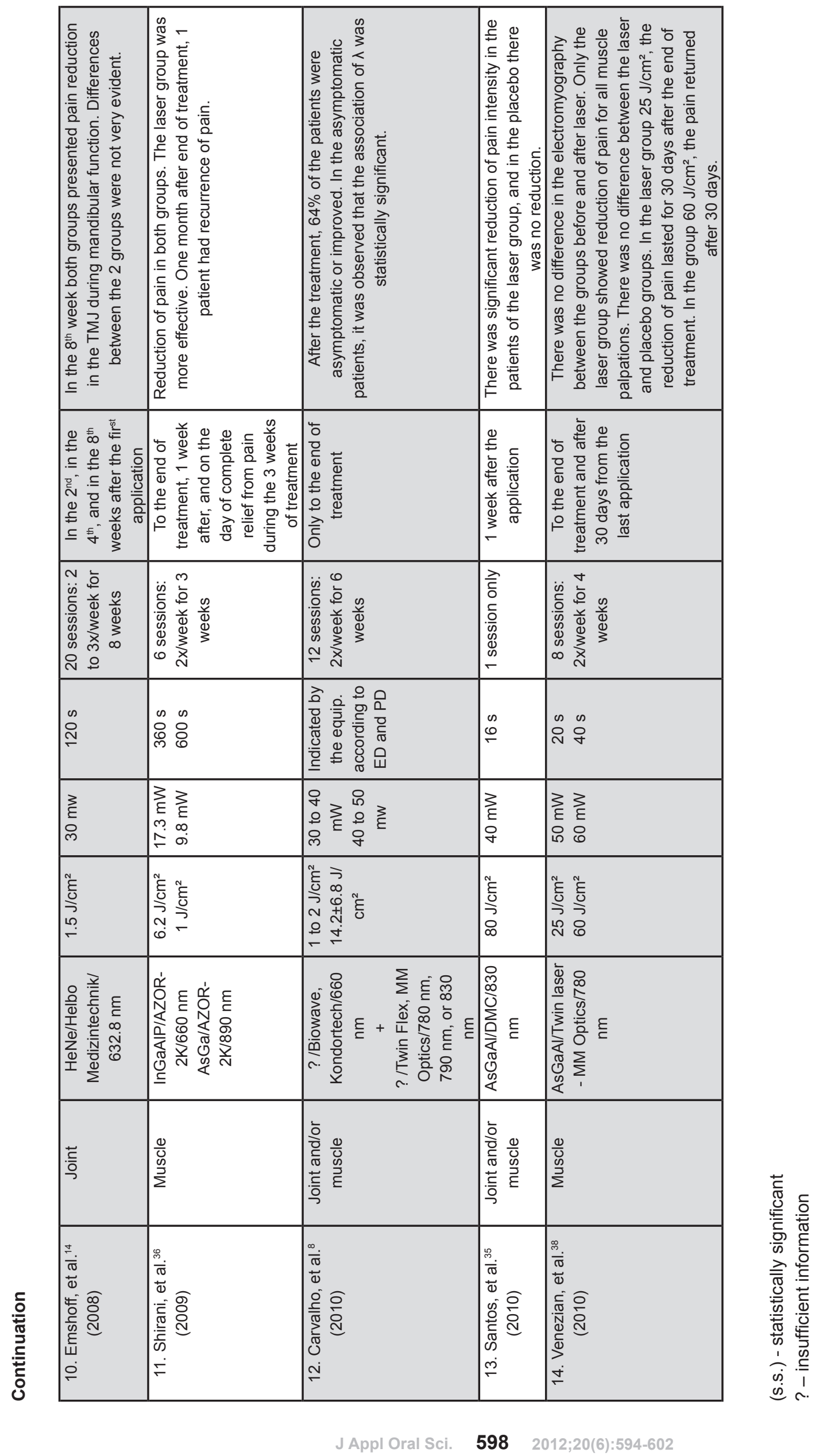


number of items in each stage,

- characteristics of the sample from each study,

- parameters used for the LLLT in each study.

At the end of paper selection process, only 14 met the specific inclusion criteria, being seven from Brazil (studies 2, 6, 7, 8, 12, 13, 14), one from Peru (study 1 ), one from Turkey (study 3 ), one from the Czech Republic (study 4), one from Cuba (study 5), two from Iran (studies 9, 11), and one from Austria (study 10) (Figure 2). The number of patients involved in the intervention process ranged from fourteen [8] to eighty [4] per group (Figure 2). In all the studies in this systematic review, there was a higher prevalence of women compared to men.

The results showed that, from the 14 selected studies, $12(1,2,3,4,6,7,8,9,10,11,13,14)$ included a placebo control group, while one (5) compared the intervention with laser to that with pharmacology and did not include a placebo group, and one study (12) evaluated only the experimental group (Figure 2 ).

Regarding the methods used for the diagnosis of TMD, 4 studies $(3,4,10,14)$ used the diagnostic criteria for TMD proposed by the "Research Diagnostic Criteria" (RDC/TMD). Most studies (1, 2, $7,9,10,11,12,13,14)$ only evaluated the signs and symptoms of TMD, quantifying pain by the Visual Analogue Scale (VAS) (Figure 2).

Some studies, in addition to performing the TMD diagnosis and assessment of pain intensity, made use of additional tests of the masticatory function, such as electromyographic evaluation (14), pressure pain threshold determination (2), and chewing efficiency (8) (Figure 2).

In terms of sites of laser application, seven studies $(1,3,4,7,9,12,13)$ beamed the laser into the joint and/or the affected muscles. Three others $(6,8,10)$ applied the laser only at the TMJ. Laser irradiation only in the affected muscles was performed in two studies $(11,14)$, while one study performed applications at acupuncture points as well as the TMJ (5) (Figure 3). Moreover, it is noteworthy that seven studies $(1,3,7,11,12,13$, 14) made application of laser light at the points of greatest pain of the patient, and the rest of the works irradiated pre-established points, whether or not they were points of greatest pain.

In relation to the wavelengths used in the studies, it was found that $\operatorname{six}(1,3,4,7,9,13)$ conducted applications in the infrared range, 5 (2, $6,8,10,14)$ used the red wavelength, 2 studies $(11,12)$ did a combination of red and infrared, and one study (5) did not specify the wavelength used (Figure 3).

The energy and power density settings, time of laser application, frequency and number of sessions, and periods of re-evaluation/follow-up are shown in Figure 3. A great variability in the parameters utilized can be seen. The energy density used in the studies ranged from $0.9 \mathrm{~J} / \mathrm{cm}^{2}$ to 105 $\mathrm{J} / \mathrm{cm}^{2}$, and the power density ranged from $9.8 \mathrm{~mW}$ to $500 \mathrm{~mW}$. In relation to application time, some studies suggest the amount of total elapsed time applied to all points in a session, while others seem to inform the time applied to each point; however, this information was not clear in the papers. It is noteworthy that there was insufficient information for the items covered in this paragraph in some studies, as seen in Figure 3.

The number of sessions of laser applications varied from one session (13) to twenty (10), as well as the frequency of applications ranging from daily for 10 consecutive days (5) to 1 time per week for 4 consecutive weeks (7). The re-evaluation periods ranged from 1 week $(11,13)$ to 12 months after the last application (9) (Figure 3).

The effectiveness of laser photobiomodulation is shown in Figure 3. It can be noted that only one study (10) observed that, at the end, both placebo and treatment groups that received laser intervention had shown pain in the TMJ during mandibular function. The other studies showed a reduction of pain after the end of the laser photobiomodulation sessions, of which in $9(3,4,5$, $6,8,9,12,13,14)$ pain was significantly reduced only in the group receiving laser intervention, and in $4(1,2,7,11)$ relief of painful symptoms occurred in both the laser and placebo groups.

\section{DISCUSSION}

Musculoskeletal condition, like TMD are the major cause of non-dental pain in the orofacial region ${ }^{24}$. Epidemiological studies estimate that $40 \%$ to $75 \%$ of the population, have at least one sign of TMD, while $33 \%$ have at least one symptom such as facial or TMJ pain ${ }^{13}$. Currently, it is disturbing to see the number of patients with TMD treated with nonevidence-based therapies ${ }^{6}$, often without competent professional assistance ${ }^{37}$. As an alternative therapy, LLLT with its analgesic, anti-inflammatory, antiedematous, and biostimulatory effects has proven to be effective in reducing pain and muscle tension in patients with $\operatorname{TMD}^{7,9,16,21,23,26,35,38}$.

LLLT is considered a safe therapeutic procedure, with well-established indications and contraindications well established through positive clinical trials, scientific investigations of the tissue changes that it promotes, and above all a better understanding of its mechanism of action ${ }^{29}$.

In 2004, the World Association of Laser Therapy approved an agreement on the format of clinical studies with LLLT for muscle and joint pain. This document established the mandatory presence of a placebo group as part of the study design. Corroborating these guidelines, this review found 
that the majority of studies used a placebo group, except for the work done by Carvalho, et al. ${ }^{8}$ (2010), who only used the experimental group that received the LLLT, and León, Almagro and García 23 (2007), who compared the group that received laser intervention with another that received pharmacological treatment.

There still no consensus on the way TMD diagnosis and measurement of the presence and severity of pain is used by researchers and clinicians. For diagnosis of individual cases, a detailed history is still the most important procedure in formulating the initial diagnostic impression. Physical examination, consisting of muscle and TMD palpation, measurement of mandibular active range of motion, and joint noise analysis, when performed by trained professionals, are important steps in the diagnosis and formulation of management strategies, as well as in monitoring the effectiveness of proposed treatments ${ }^{13}$. Accordingly, in this review it was found that only four studies $9,14,16,38$ diagnosed TMD according to the criteria proposed by the Research Diagnostic Criteria for Temporomandibular Disorders, with are widely used for diagnosis of TMD. However, none of these identified the severity of TMD in their patients which is of paramount importance since TMD may also be present in a sub-clinical form. As can be observed in the papers included in the present review, there are no standardization of the diagnostic criteria, which is a limitation of most of systematic reviews involving musculoskeletal conditions as TMD.

Studies using auxiliary methods of diagnosis, as Shirani, et al. ${ }^{36}$ (2009), who made use of computerized tomography and magnetic resonance imaging of the TMJ, and Venancio, Camparis and Lizarelli $^{37}$ (2005); Mazzetto, et al. ${ }^{26}$ (2007); and Carrasco, et al.7 (2008), who used panoramic radiography, should be analyzed with caution because there is not always a direct association between the findings of such examinations and the presence of signs and symptoms of TMD ${ }^{1,33}$.

The use of LLLT for musculoskeletal disorders is based on the irradiation of some specific and interrelated areas: the painful area, triggerpoints and the area of referred pain as well as in acupuncture points. With this in mind, the studies of Kulekcioglu, et al. ${ }^{20}$ (2003); Çetiner, Kahraman and Yücetaş ${ }^{9}$ (2006); Fikácková, et al. ${ }^{16}$ (2007); Cunha, et al. ${ }^{11}$ (2008); Santos, et al. ${ }^{35}$ (2010); and Carvalho, et al. $^{8}$ (2010) did irradiation on the affected area and on areas of referred pain, according to patient symptoms. In contrast, Mazzetto, et al. ${ }^{26}$ (2007), Carrasco, et al. ${ }^{7}$ (2008), and Emshoff, et al.14 (2008) only performed the application at the TMJ. Shirani, et al. ${ }^{39}$ (2009) and Venezian, et al. ${ }^{38}$ (2010) made the application only in the muscle region; and León, Almagro and García ${ }^{23}$ (2007) made the application on acupuncture points: gallbladder, stomach, and TMJ. Furthermore, it is useful to remind that the antiinflammatory and analgesic effects of laser light occur only in the affected tissue, which explains the importance of muscle and joint palpation for the identification of points causing the patient's pain. Based on this context, only seven studies $^{9,11,13,19,24,38,42}$ established laser application at the point of greatest pain, while the rest made the application on pre-established points.

Lasers with an infrared wavelength are the most suitable due to their greater penetration. The most commonly used are located in the electromagnetic spectrum from 780 to $904 \mathrm{~nm}^{37}$. The findings of Kulekcioglu, et al. ${ }^{20}$ (2003); Venancio, Camparis and Lizarelli37 (2005); Çetiner, Kahraman and Yücetaş ${ }^{9}$ (2006); Fikácková, et al. ${ }^{16}$ (2007); Mazzetto, et al.26 (2007); Carrasco, et al. ${ }^{7}$ (2008); Cunha, et al. ${ }^{11}$ (2008); Lassemi, et al. ${ }^{21}$ (2008); Santos, et al. ${ }^{35}$ (2010); and Venezian, et al. ${ }^{38}$ (2010) corroborate the above data using wavelengths in the infrared range, whose electromagnetic spectra varied from $780 \mathrm{~nm}$ to $980 \mathrm{~nm}$. In contrast, Emshoff, et al. ${ }^{14}$ (2008) did not corroborate with the above authors and used a wavelength in the red range. However, Carvalho, et al. ${ }^{8}$ (2010) performed a combination of the two wavelengths, red and infrared.

The efficacy of adjuvant therapy has been proven by several studies as cited above. However, the interaction of laser light with tissue can lead to different results. These results depend on several factors such as the wavelength, energy density, and power density, as well as the optical properties of tissue ${ }^{39}$. Therefore, many studies have been conducted in order to reach a consensus on the intensity, exposure time, and site of laser application $^{10}$.

In terms of frequency and number of laser sessions applied, Mazzetto, et al. ${ }^{26}$ (2007), Carrasco, et al. ${ }^{7}$ (2008), and Venezian, et al. ${ }^{38}$ (2010) argued for eight sessions with applications twice per week. Venancio, Camparis and Lizarelli37 (2005) and Shirani, et al. ${ }^{36}$ (2009) established the use of six sessions with a frequency of twice per week. Çetiner, Kahraman and Yücetaş ${ }^{9}$ (2006); Fikácková, et al. ${ }^{16}$ (2007); and León, Almagro and García 23 (2007) argued for 10 sessions; however, each one established different application frequencies.

Studies that have shown the greatest laser photobiomodulation effectiveness appear to be linked to higher irradiation protocols (energy density and/or power density) as well as to a greater number of sessions and frequency of application. It was also noted that, of the eight studies that showed the best results, four applied laser to the points of greatest pain, whether joint or muscle, while the other four applied laser to pre-established points. 
The studies of Çetiner, Kahraman and Yücetaş ${ }^{9}$ (2006); Mazzetto, et al. ${ }^{26}$ (2007); and Venezian, et al. ${ }^{38}$ (2010) did a follow-up of patients 30 days after the last irradiation. Çetiner, Kahraman and Yücetaş ${ }^{9}$ (2006) and Venezian, et al. ${ }^{38}$ (2010) found that pain reduction remained statistically significant during this period, while Mazzetto, et al. ${ }^{26}$ (2007) found that the least tenderness to palpation was seen at the last session of laser application. Lassemi, et al. ${ }^{21}$ (2008) followed patients for 2 years and observed significant results for both pain reduction and for clicking. Although most studies of this review did not make use of a patient follow-up period, it may be suggested that for those who carried out the follow-up, the laser applications promoted a relief of painful symptomatology for at least 30 days after the last irradiation.

As can be seen here, there is still no consensus on the best parameters and standards of laser photobiomodulation and, therefore, the definition of the best treatment protocol and clinical recommendation to be used in cases of TMD pain is not possible at the present time.

However, it seems clear that the use of laser brings benefits when properly applied and administered, although the exact mechanism of action is still to be defined. In some studies, it was noted that the results of LLLT were minimum possibly due to the absence of a specific protocol. This difficulty in the establishment of specific irradiation parameters for a particular area is also observed in other fields such as physical therapy and medicine, for example. Recently, for the area of physical therapy, specific guidelines have been published and studies are being performed to test the efficacy of LLLT. Therefore, it is imperative to also draw up specific guidelines for dentistry, as its applicability in this area is extensive, widespread, and extremely important for the control of pain and/or inflammation of the masticatory muscles and temporomandibular joint.

In short, the results allow us to suggest that the effectiveness of LLLT is more accentuated when using the laser in wavelengths in the infrared region of light spectrum, as well as with higher irradiation protocols (energy density and/or power density) and a larger number of sessions and frequency of application.

\section{CONCLUSION}

Most papers, including those using a doubleblind and placebo-controlled trial, showed that LLLT seemed to be effective in reducing pain from TMD. However, the heterogeneity of the standardization regarding the parameters of laser calls for caution in interpretation of these results. A potential explanation for the LLLT positive results in reducing pain levels could be a dose-specific antiinflammatory, healing and analgesic effect in TMJ as well as in the masticatory muscle painful area. However, more studies are needed to precisely determine optimal treatment procedures and parameters for LLLT in TMD.

\section{ACKNOWLEDGEMENTS}

\section{M.L.M.M is recipient of CAPES scholarship grant.}

\section{REFERENCES}

1- Ahmad M, Hollender L, Anderson Q, Kartha K, Ohrbach R, Truelove $E L$, et al. Research diagnostic criteria for temporomandibular disorders (RDC/TMD): development of image analysis criteria and examiner reliability for image analysis. Oral Surg Oral Med Oral Pathol Oral Radiol Endod. 2009;107:844-60.

2- Albertin A, Kerppers II, Amorim CF, Costa RV, Ferrari Corrêa JC, Oliveira CS. The effect of manual therapy on masseter muscle pain and spasm. Electromyogr Clin Neurophysiol. 2010;50:107-12. 3- Bjordal MJ, Couppé C, Chow RT, Tunér J, Ljunggren EA. A systematic review of low level laser therapy with location-specific doses for pain from chronic joint disorders. Austr J Physiother. 2003;49:107-16.

4- Bonjardim LR, Lopes-Filho RJ, Amado G, Albuquerque $\mathrm{RL}$ Jr, Gonçalves SR. Association between symptoms of temporomandibular disorders and gender, morphological occlusion, and psychological factors in a group of university students. Indian J Dent Res. 2009;20:190-4.

5- Bove SRK, Guimarães AS, Smith RL. Characterization of patients in a temporomandibular dysfunction and orofacial pain outpatient clinic. Rev Lat Am Enfermagem. 2005;13:686-91.

6- Bucci MB, Aversa M, Guarda-Nardini L, Manfredini D. Occlusion and temporomandibular disorders: a malpractice case with medical legal considerations. Minerva Stomatol. 2011;60(1-2):65-74.

7- Carrasco TG, Mazzetto MO, Mazzetto RG, Mestriner W Jr. Low intensity laser therapy in temporomandibular disorder: a phase II double-blind study. Cranio. 2008;26:274-81.

8- Carvalho CM, Lacerda JA, Santos Neto FP, Cangussu MC, Marques AM, Pinheiro ALB. Wavelength effect in temporomandibular joint pain: a clinical experience. Lasers Med Sci. 2010;25:229-32.

9- Çetiner S, Kahraman SA, Yücetaş Ş. Evaluation of low-level laser therapy in the treatment of temporomandibular disorders. Photomed Laser Surg. 2006;24:637-41.

10- Conti P. Low level laser therapy in the treatment of temporomandibular disorders (TMD): a double-blind pilot study. J Craniomandib Pract. 1997;15:144-9.

11- Cunha LA, Firoozmand LM, Silva AP, Esteves SA, Oliveira W. Efficacy of low-level laser therapy in the treatment of temporomandibular disorder. Int Dent J. 2008;58:213-7.

12- De Kanter RJ, Truin GJ, Burgersdijk RC, Van't Hof MA, Batistuzzi $P G$, Kalsbeek $H$, et al. Prevalence in the Dutch adult population and a meta-analysis of signs and symptoms of temporomandibular disorder. J Dent Res. 1993;72:1509-18.

13- De Leeuw R. Orofacial pain: guidelines for assessment, diagnosis and management. $4^{\text {th }}$ ed. Chicago: Quintessence; 2008. 14- Emshoff R, Bösch R, Pümpel E, Schöning H, Srobl H. Low-level laser therapy for treatment of temporomandibular joint pain: a double-blind and placebo-controlled trial. Oral Surg Oral Med Oral Pathol Oral Radiol Endod. 2008;105:452-6.

15- Esposito CJ, Veal SJ, Farmam AG. Alleviation of myofascial pain with ultrasonic therapy. J Prosthet Dent. 1984;51:106-8.

16- Fikácková H, Dostálová T, Navrátil L, Klaschka J. Effectiveness of low-level laser therapy in temporomandibular joint disorders: a placebo-controlled study. Photomed Laser Surg. 2007;25(4):297303. 
17- Gesch D, Bernhardt O, Alte D, Schwahn C, Kocher T, John U, et al. Prevalence of signs and symptoms of temporomandibular disorders in an urban and rural German population: results of a population-based study of health in Pomerania. Quintessence Int. 2004;35:143-50.

18- Karu TI, Afanasyeva NI, Kolyakov SF, Pyatibrat LV, Welser L. Changes in absorbance of monolayer of living cells induced by laser irradiation at 633,670, and $820 \mathrm{~nm}$. IEEE J Sel Top Quantum Electron. 2001;7:982-8.

19- Kato MT, Kogawa EM, Santos CN, Conti PCR. TENS and lowlevel laser therapy in the management of temporomandibular disorders. J Appl Oral Sci. 2006;14:130-5.

20- Kulekcioglu S, Sivrioglu K, Ozcan O, Parlak M. Effectiveness of low-level laser therapy in temporomandibular disorder. Scand J Rheumatol. 2003;32:114-8.

21- Lassemi E, Jafari SM, Motamedi MHK, Navi F, Lasemi R. Lowlevel laser therapy in the management of temporamandibular joint disorder. J Oral Laser Applications. 2008;8:83-6.

22- La Touche R, Goddard G, De-la-Hoz JL, Wang K, Paris-Alemany A, Angulo-Díaz-Parreño $S$, et al. Acupuncture in the treatment of pain in temporomandibular disorders: a systematic review and meta-analysis of randomized controlled trials. Clin J Pain. 2010;26:541-50.

23- León IG, Almagro S, García RC. Los trastornos temporomandibulares y la radiación láser. Rev-Cubana Estomatol. 2007;44(3):1-8.

24- List T, Axelsson S. Management of TMD: evidence from systematic reviews and meta-analyses. J Oral Rehabil. 2010;37:430-51.

25- Magnusson T, Egemark I, Carlsson GE. A Iongitudinal epidemiologic study of signs and symptoms of temporomandibular disorders from 15 to 35 years of age. J Orofac Pain. 2000;14:3109.

26- Mazzetto MO, Carrasco TG, Bidinelo EF, Pizzo RCA, Mazzettp RG. Low intensity laser application in temporomandibular disorders: a phase I double-blind study. Cranio. 2007;25:186-92. 27- Mazzetto MO, Hotta TH, Pizzo RCA. Measurements of jaw movements and TMJ pain intensity in patients treated with GaAlAs laser. Braz Dent J. 2010;21:356-60.

28- Öz S, Gökçen-Röhlig B, Saruhanoglu A, Tuncer EB. Management of myofascial pain: low-level laser therapy versus occlusal splints. J Craniofac Surg. 2010;21:1722-8.
29- Pesevska S, Nakova M, Pejcic A, Ivanovski K, Angelov N, Mindova S. Biostimulative Laser Therapy: base for favorized and accented results in Dentistry. Acta Fac Med Naiss. 2006;23:75-8. 30- Phillips JM, Gatchel RJ, Wesley AL, Ellis E $3^{\text {rd }}$. Clinical implications of sex in acute temporomandibular disorders. J Am Dent Assoc. 2001;132:49-57.

31- Pinheiro ALB, Cavalcanti ET, Pinheiro TI, Alves MJ Miranda ER, Quevedo AS, et al. Low-level laser therapy is an important tool to treat disorders of the maxillofacial region. J Clin Laser Med Surg. 1998;16:223-6.

32- Rodrigues D, Siriani AO, Bérzin F. Effect of conventional TENS on pain and electromyographic activity of masticatory muscles in TMD patients. Braz Oral Res. 2004;18:290-5.

33- Rossetti LM, Araujo CRP, Rossetti PH, Conti PC. Association between rhythmic masticatory muscle activity during sleep and masticatory myofascial pain: a polysomnographic study. J Orofac Pain. 2008;22:190-200.

34- Salonen L, Hellden L, Carlsson G. Prevalence of signs and symptoms of dysfunction in the masticatory system: an epidemiologic study in an adult Swedish population. J Craniomandib Disord. 1990;4:241-50.

35- Santos TS, Piva MR, Ribeiro MH, Antunes AA, Melo AR, Silva ED. Lasertherapy efficacy in temporomandibular disorders: control study. Braz J Otorhinolaryngol. 2010;76:294-9.

36- Shirani AM, Gutknecht N, Taghizadeh M, Mir M. Low-level laser therapy and myofacial pain dysfunction syndrome: a randomized controlled clinical trial. Lasers Med Sci. 2009;24:715-20.

37- Venancio RA, Camparis CM, Lizarelli RF. Low intensity laser therapy in the treatment of temporomandibular disorders: a double-blind study. J Oral Rehabil. 2005;32:800-7.

38- Venezian GC, Silva MA, Mazzetto RG, Mazzetto MO. Low level laser effects on pain to palpation and electromyographic activity in TMD patients: a double-blind, randomized, placebo-controlled study. Cranio. 2010;28:84-91.

39- Werneck CE, Pinheiro AL, Pacheco MT, Soares CP, Castro JL. Laser light is capable of inducing proliferation of carcinoma cells in culture: a spectroscopic in vitro study. Photomed Laser Surg. 2005;23:300-3. 